\title{
openheart Internationally validated score to predict the outcome of non-paroxysmal atrial fibrillation ablation: the 'FLAME score'
}

\author{
Vennela Boyalla (DD , ,,2 Julian W E Jarman, ${ }^{1,2}$ Vias Markides, ${ }^{1,2}$ Wajid Hussain, ${ }^{1,2}$ \\ Tom Wong, ${ }^{1,2} \mathrm{R}$ Hardwin Mead, ${ }^{3}$ Gregory Engel, ${ }^{3}$ Melissa H Kong, ${ }^{3}$
} Rob A Patrawala, ${ }^{3}$ Roger A Winkle ${ }^{3}$

\begin{abstract}
- Additional online supplemental material is published online only. To view, please visit the journal online (http://dx.doi.org/10.1136/ openhrt-2021-001653).
\end{abstract}

To cite: Boyalla V, Jarman JWE, Markides V, et al. Internationally validated score to predict the outcome of non-paroxysmal atrial fibrillation ablation: the 'FLAME score'. Open Heart 2021;8:e001653. doi:10.1136/ openhrt-2021-001653

Received 15 March 2021 Accepted 13 July 2021
Check for updates

(C) Author(s) (or their employer(s)) 2021. Re-use permitted under CC BY-NC. No commercial re-use. See rights and permissions. Published by BMJ.

${ }^{1}$ Heart Division, Royal Brompton and Harefield Hospitals, London, UK

${ }^{2}$ National Heart \& Lung Institute, Imperial College London,

London, London, UK

${ }^{3}$ Silicon Valley Cardiology, East Palo Alto, California, USA

Correspondence to Dr Vias Markides; v.markides@ rbht.nhs.uk

\section{ABSTRACT}

Background The clinical effectiveness of ablating nonparoxysmal atrial fibrillation (non-PAF) relies on proper patient selection. We developed and validated a scoring system to predict non-PAF ablation outcomes.

Methods Data on 416 non-PAF ablations were analysed using binary logistic regression at a London centre. Identified preprocedural variables, which independently predicted freedom from atrial tachyarrhythmia. Twenty-one possible predictive variables and a model with c-statistic 0.751 - explained outcome variation in London at mean follow-up $12 \pm 3$ months. An additive point score (range $0-9$ ) was developed - the FLAME score: female $=1$; longlasting persistent atrial fibrillation $=1$; left atrial diameter in $\mathrm{mm}: 40$ to $<45=1,45$ to $<50=2,50$ to $<55=3, \geq 55$ $=4$; mitral regurgitation $(\mathrm{MR})$ mild to moderate $=1$; extreme comorbidity $=2$. Extreme comorbidities include severe MR, moderate mitral stenosis, mitral replacement, hypertrophic cardiomyopathy or congenital heart disease.

Results The FLAME score was applied to data (882 non-PAF ablations) at a Californian centre, and predicted the outcome of both single $(p<0.0001)$ and multiple $(p<0.0001)$ procedures. For first ablation (follow-up 2.1 years (median, IQR 1.0-4.1)), FLAME score: $0-1$ predicts $62 \%$ success, $2-444 \%$ and $\geq 529 \%\left(P_{\text {trend }}<0.0001\right)$. After the final ablation (mean procedures: $1.4 \pm 0.6$, follow-up 1.8 years (median, IQR 0.8-3.6)), FLAME score: $0-1$ predicts $81 \%$ success, $2-465 \%$ and $\geq 544 \%\left(P_{\text {trend }}\right.$ $<0.0001$ ).

Conclusions FLAME score is easily calculated, derived in London, and predicted single and multiple procedural outcomes for non-PAF ablations in California. In patients with a high score, even multiple procedures are usually ineffective.

\section{INTRODUCTION}

Catheter ablation is an effective treatment for most patients with symptomatic paroxysmal atrial fibrillation (AF), establishing its superiority over antiarrhythmic drugs (AADs) in restoring sinus rhythm in multiple randomised controlled trials. ${ }^{12}$ However, its efficacy at treating non-paroxysmal AF (PAF) is lower, ${ }^{3}$ with long-term maintenance of sinus rhythm following a single procedure below

\section{Key questions}

What is already known about this subject?

- Numerous predictive scores have been developed over the last decade to determine outcomes for patients undergoing catheter ablation for atrial fibrillation (AF). However, these scores were developed for all types of AF, from paroxysmal AF (PAF) to nonPAF. Success rates for ablating patients with PAF are high, and therefore, prediction scores are of limited use in this subtype. Conversely, the non-PAF cohort is difficult to treat with lower success rates following ablation.

What does this study add?

- The Female, Long-lasting, Atrial diameter, Mitral, Extreme score is the first outcome prediction tool focusing only on the non-PAF population undergoing catheter ablation. It is easy to calculate based on baseline clinical variables (history, sex and echocardiography). The majority of patients with non-PAF require more than one procedure to achieve sinus rhythm. The score can stratify patients both for first and multiprocedural outcomes after catheter ablation.

How might this impact on clinical practice?

- Primarily, the impact of this score will be precision medicine, giving clinicians a tool to analyse individual patient risk for ablation outcomes. Secondarily and more importantly is to educate patients by setting expectations for their ablation journey.

$30 \%$ in some studies, ${ }^{4}$ although improvement beyond $70 \%$ with multiple procedures has been reported. ${ }^{45}$

Internationally practice has gravitated towards offering catheter ablation as first-line treatment for symptomatic PAF, given a clear trajectory evidenced by high success rates. ${ }^{2}$ However, the success rate in ablating non-PAF is highly variable, $^{4}{ }^{5}$ therefore, appropriate patient selection is paramount. A scoring system for non-PAF, predicting successful restoration of sinus rhythm after single or multiple ablations, would be invaluable for guiding patients before 
embarking on an invasive treatment journey. Such a score has not been recommended in international guidelines, despite evidence correlating catheter ablation outcomes with several clinical variables, ${ }^{36}$ such as left atrial (LA) diameter and duration of non-PAF.

We developed an internationally relevant scoring system by first identifying baseline clinical variables independently predictive of a successful outcome of catheter ablation of non-PAF at a hospital in London (UK) and derived a scoring system to predict procedural outcomes. We then externally validated this scoring system among an independent cohort of patients at a hospital in California (USA).

\section{METHODS}

\section{Score development: London}

The Royal Brompton \& Harefield Hospitals (London, UK) are a specialist heart and lung centre in which seven cardiologists were performing catheter ablation (procedural details are in online supplemental material) for non-PAF. As a national referral centre, the casemix is relatively complex, including patients with adult congenital heart disease. All patients provided informed written consent. Patients are reviewed regularly during the year after discharge, with ambulatory 24-hour ECG recordings to document arrhythmias standardly performed at 6 and 12 months postoperatively, and additional 7-day ECG recordings performed as required in response to symptoms. AADs were discontinued at the discretion of the clinician.

We retrospectively reviewed the records of all patients who underwent initial or redo non-PAF catheter ablations during this period. Redo procedures, following the first procedure for non-PAF, were included where the recurrent arrhythmia was PAF, non-PAF or LA tachycardia (AT). The individual procedure outcome (IPO), the outcome following an initial or redo procedure. This was defined as successful if, following the procedure examined, there was an absence of greater than 30s of atrial arrhythmia (fibrillation, flutter or tachycardia) based on symptoms and ambulatory ECG recordings, at all follow-up visits following a 'blanking period' of 3 months.

We examined 17 preoperative clinical variables (table 1 ) as possible predictors of IPO, as well as whether a redo procedure, the number of previous ablations, presence of AT in redo procedures and follow-up duration. Longstanding persistent $\mathrm{AF}$ was defined as continuous $\mathrm{AF}$ of greater than 12 months' duration. One clinical variable, 'extreme comorbidity', was a composite of rarely occurring comorbidities thought likely to reduce the chance of success but difficult to examine individually. Extreme comorbidity was defined as the presence of any one of severe mitral regurgitation (MR), moderate or severe mitral stenosis, mitral valve replacement, hypertrophic cardiomyopathy or structural congenital heart disease with significant ongoing haemodynamic impact on the atria. It is also important to note that rate control, usually with beta-blockers, was offered to all patients with appropriate dose titration. In those with new left ventricular dysfunction, electrical cardioversion, often aided by concomitant administration of AADs such as amiodarone, was also frequently offered and performed.

We performed univariate analysis to identify variables associated with IPO and then entered possible explanatory variables into a multivariate binary logistic regression analysis sequentially to construct a model to explain the variation in IPO as the dependent variable. Using baseline clinical variables independently predictive of IPO, we then constructed an additive point score-the 'Female, Long-lasting, Atrial diameter, Mitral, Extreme (FLAME) score'- to predict non-PAF ablation outcomes.

\section{Score testing: California}

Silicon Valley Cardiology (California, USA) is a specialist cardiac centre where four cardiologists were performing catheter ablation for patients with non-PAF. All patients provided informed written consent. The catheter ablation techniques employed were similar to those in London (further details in online supplemental material). There was no significant change in procedural outcomes for non-PAF during the period studied. ${ }^{7}$ Follow-up arrangements were similar to those in London, and AADs were discontinued in all patients.

Data on all patients who underwent initial or redo non-PAF catheter ablations during this period were collected prospectively. Inclusion criteria were the same as those employed in London. We examined the outcome following the patient's first procedure and their final procedure. For both procedures, success was defined in the same way as in London. Kaplan-Meier analysis and calculation of the c-statistic were used to determine the predictive accuracy of the FLAME score, and Ptrend (Mantel-Haenszel test) was used as a test for trend in success rate as the FLAME score increases.

\section{Statistical analysis}

Population differences were evaluated with Pearson's $\chi^{2}$ test (categorical data), Kruskal-Wallis test ( $>2$ categories), and Student's t-test (continuous data). Univariate relationships to IPO used Pearson's $\chi^{2}$ or Fisher's exact test (categorical data), Mantel-Haenszel test of trend ( $>2$ categories) and Student's t-test (continuous data). Tests were performed two tailed, and values of $\mathrm{p}<0.05$ were considered statistically significant. Variables were entered into multivariate stepwise binary logistic regression in order of univariate significance, with IPO the dependent variable. Variables with $\mathrm{p}<0.05$ in multivariate analysis, or borderline significance but clinically relevant, were retained in the final model and the c-statistic and Hosmer-Lemeshow test calculated. An adjustment was not made for multiple testing as reported results are explorative. Kaplan-Meier log-rank testing and c-statistic calculation quantified the predictive accuracy of the score. MantelHaenszel test of trend assessed stepwise change in success rate by score. Time at risk was accounted for in London data by including follow-up duration in multivariate analysis and in Californian data with Kaplan-Meier log-rank testing. 
Arrhythmias and sudden death

Table 1 Population characteristics in London and California

\begin{tabular}{|c|c|c|c|}
\hline \multirow[b]{3}{*}{ Variable } & London & California & \multirow[b]{3}{*}{$P$ value } \\
\hline & Per patient & Per patient & \\
\hline & $(n=361)$ & $(n=619)$ & \\
\hline Age (years, mean $\pm S D$ ) & $60 \pm 11$ & $63 \pm 10$ & $0.001^{*}$ \\
\hline Female sex & $98(27)$ & $153(25)$ & 0.401 \\
\hline Body mass index $\left(\mathrm{kg} / \mathrm{m}^{2}\right.$, mean $\left.\pm \mathrm{SD}\right)$ & $29 \pm 6$ & $30 \pm 5$ & 0.133 \\
\hline Long-standing persistent AF (>1 year) & $105(29)$ & $157(25)$ & 0.204 \\
\hline Left atrial diameter $(\mathrm{mm}$, mean $\pm \mathrm{SD}) \dagger$ & $47 \pm 8$ & $45 \pm 7$ & $<0.0001^{*}$ \\
\hline \multicolumn{2}{|l|}{ Left ventricular function } & & $<0.0001^{*}$ \\
\hline Normal & $232(64)$ & $448(72)$ & \\
\hline Mildly impaired & $50(14)$ & $122(20)$ & \\
\hline Moderately impaired & $38(11)$ & $33(5)$ & \\
\hline Severely impaired & $41(11)$ & $16(3)$ & \\
\hline Valvular heart disease $\neq$ & $38(11)$ & $49(8)$ & 0.166 \\
\hline Extreme comorbidity§ & $39(11)$ & $27(4)$ & $0.0001^{*}$ \\
\hline Hypertension & $105(29)$ & $318(51)$ & $<0.0001^{*}$ \\
\hline Diabetes mellitus & $29(8)$ & $67(11)$ & 0.156 \\
\hline Coronary artery disease & $53(15)$ & $90(15)$ & 1.000 \\
\hline Thyrotoxicosis within the last year & $11(3)$ & $13(2)$ & 0.355 \\
\hline Pulmonary disease & $10(3)$ & $38(6)$ & $0.002^{*}$ \\
\hline Stroke or TIA & $21(6)$ & $48(6)$ & 0.253 \\
\hline Renal dysfunction & $5(1)$ & $\mathrm{N} / \mathrm{A}$ & $\mathrm{N} / \mathrm{A}$ \\
\hline Previous antiarrhythmic drugs (median(IQR) $)^{\star \star}$ & $1(0-1)$ & $1(1-2)$ & $<0.0001^{*}$ \\
\hline Previous use of amiodarone & $115(32)$ & $209(34)$ & 0.540 \\
\hline \multirow[t]{3}{*}{ FLAME score $($ mean $\pm S D)$} & $2.9 \pm 1.7$ & $2.5 \pm 1.6$ & $<0.0001^{*}$ \\
\hline & Per procedure & Per patient & \\
\hline & $(\mathrm{n}=416)$ & $(n=619)$ & \\
\hline Follow-up (months, mean \pm SD/median (IQR)) & $12 \pm 3$ & $25(12-50)$ & $<0.0001^{*}$ \\
\hline
\end{tabular}

Values shown are number (\%) unless otherwise indicated. Per patient values are calculated at the time of a patient's first procedure.

*Statistically significant $p<0.05$.

†Transthoracic echocardiographic left parasternal long axis anteroposterior diameter at end-systole.

¥Moderate or greater stenosis or regurgitation, replacement or repair of any left-sided valve.

$\S$ See figure 1 for definition

१Thyrotoxic within the last year.

${ }^{\star *}$ Class I or III agents.

AF, atrial fibrillation; FLAME, Female, Long-lasting, Atrial diameter, Mitral, Extreme; N/A, not available; TIA, transient ischaemic attack.

Patients were censored at the time of failure or last follow-up. Analyses were performed using IBM SPSS Statistics software (V.20, IBM).

\section{RESULTS}

\section{Score development: London}

A total of 416 procedures were examined in London among 361 patients. Patients' baseline characteristics are summarised in table 1 . The mean duration of follow-up was $12 \pm 3$ months. AADs were discontinued following 368 $(88 \%)$ procedures. Univariate and multivariate analyses of variables possibly predictive of the IPO are shown in table 2. By univariate analysis, significantly lower chance of therapy success was predicted by long-standing persistent AF $>1$ year $(\mathrm{p}<0.0001)$, increasing duration of follow-up $(\mathrm{p}<0.0001)$, increasing LA diameter $(\mathrm{p}=0.001)$, extreme comorbidity $(\mathrm{p}=0.001)$, lower age $(\mathrm{p}=0.002)$, recent thyrotoxicosis $(\mathrm{p}=0.006)$, previous use of amiodarone $(\mathrm{p}=0.008)$, increasing number of previous AADs $(p=0.013)$ and female sex (borderline significance, $\mathrm{p}=0.051)$.

By multivariate analysis, a model with c-statistic 0.751 (95\% CI, 0.701 to 0.801 (Hosmer-Lemeshow test $=0.632$ ) was constructed from variables independently predictive of significantly lower chance of therapy success: long-standing persistent AF $>1$ year $(p=0.001)$, female 
Table 2 Relationship between clinical variables and procedural success in London by univariate and multivariate analysis

\begin{tabular}{|c|c|c|c|}
\hline \multirow[b]{2}{*}{ Variable } & \multirow{2}{*}{$\begin{array}{l}\text { Univariate analyses } \\
P \text { value }\end{array}$} & \multicolumn{2}{|c|}{ Multivariate analyses } \\
\hline & & $\operatorname{RR}(95 \% \mathrm{Cl})^{*}$ & $P$ value \\
\hline Long-standing persistent $\mathrm{AF}$ ( $>1$ year) & $<0.0001$ & $0.40(0.23$ to 0.70$)$ & 0.001 \\
\hline Follow-up (months) & $<0.0001$ & $0.87(0.79$ to 0.95$) \dagger$ & 0.003 \\
\hline Female sex & 0.051 & 0.44 (0.25 to 0.78$)$ & 0.005 \\
\hline Age (years) & 0.002 & & 0.006 \\
\hline$<50$ & & 0.26 (0.11 to 0.58$)$ & 0.001 \\
\hline $50-59$ & & 0.65 (0.32 to 1.32$)$ & 0.234 \\
\hline $60-69$ & & 0.81 (0.43 to 1.54$)$ & 0.517 \\
\hline$\geq 70$ & & 1.000 & 1.000 \\
\hline Thyrotoxicosis within the last year & 0.006 & 0.21 (0.06 to 0.83$)$ & 0.025 \\
\hline AT rather than $\mathrm{AF}$ (at redo procedure) & 0.122 & 2.04 (1.10 to 3.82 ) & 0.025 \\
\hline Left atrial diameter $(\mathrm{mm})$ & 0.001 & 0.96 (0.93 to 0.996)‡ & 0.028 \\
\hline Extreme comorbidity & 0.001 & 0.46 (0.21 to 1.03$)$ & $0.059^{\ddagger}$ \\
\hline Previous use of amiodarone & 0.008 & & \\
\hline Previous antiarrhythmic drugs§ & 0.013 & & \\
\hline Valvular heart disease & 0.062 & & \\
\hline Left ventricular function & 0.106 & & \\
\hline Diabetes mellitus & 0.177 & & \\
\hline Renal dysfunction & 0.178 & & \\
\hline Hypertension & 0.191 & & \\
\hline Stroke or TIA & 0.198 & & \\
\hline Any previous AF ablation & 0.327 & & \\
\hline Coronary artery disease & 0.374 & & \\
\hline Pulmonary disease & 0.429 & & \\
\hline Number previous AF ablations & 0.783 & & \\
\hline Body mass index & 0.987 & & \\
\hline
\end{tabular}

${ }^{*}$ Relative Risk $(95 \% \mathrm{Cl})$ of success, derived from binary logistic regression.

†Continuous variable; negative correlation with success.

łBorderline statistical significance

$\S$ Class I or III agents

AF, indicates atrial fibrillation; AT, atrial tachycardia; TIA, transient ischaemic attack.

sex $(\mathrm{p}=0.005)$, increasing LA diameter $(\mathrm{p}=0.028)$, presence of extreme comorbidity (borderline significance, $\mathrm{p}=0.059)$, thyrotoxicosis within the last year $(\mathrm{p}=0.025)$, age $<50$ years $(\mathrm{p}=0.006), \mathrm{AF}$ rather than AT (relevant to redo procedures) $(\mathrm{p}=0.025)$ and increasing duration of follow-up $(\mathrm{p}=0.003)$ (table 2$)$.

\section{'FLAME score'}

An additive point score (range 0-9) relevant to the selection of patients to enter a programme of catheter ablation for non-PAF was developed. Baseline clinical variables which were not modifiable and were independently predictive of therapy failure were included. As extreme comorbidity (including severe MR) had relatively few procedures to allow detailed statistical assessment of its impact and was associated with poor outcomes (22\% success), it was included despite borderline statistical significance. It was given a relatively high weighting, and the presence of mild to moderate MR was included with a lower weighting. Recent thyrotoxicosis was not included being considered modifiable. While there was an increased risk of therapy failure in patients $<50$ years, there was no significant difference in outcome among other age strata. A very high burden of comorbidity in the younger London patients (including extreme comorbidity in $14 / 78(18 \%)<50$ years vs $36 / 338(11 \%) \geq 50$ years; $\mathrm{p}=0.032)$, particularly congenital heart disease $(8 / 78(10 \%)<50$ years vs $15 / 338(4 \%) \geq 50$ years; $\mathrm{p}=0.031)$, not fully reflected by the variables present in multivariate analysis, did not appear relevant to most populations. Age was, therefore, not included in the score. The score is shown in figure 1. A model containing the score's variables alone had a c-statistic of 0.675 (95\% CI, 0.620 to 0.731 , Hosmer-Lemeshow test $=0.348)$. 


\begin{tabular}{|l|l|}
\hline Risk factor & Score \\
\hline Female sex & 1 \\
\hline Long-lasting persistent AF ( $>1$ year) & 1 \\
\hline 40 - <45 & \\
\hline $\begin{array}{l}\text { Atrial diameter (left, mm) }<55 \\
\geq 55\end{array}$ & 1 \\
\hline $\begin{array}{l}\text { Mitral regurgitation (mild to moderate) } \\
\text { Extreme comorbidity* }\end{array}$ & 2 \\
\hline $\begin{array}{l}\text { Maximum score } \\
\text {-Extreme comorbidity is any of: } \\
\text {-moderate or greater mitral stenosis } \\
\text {-mitral valve replacement } \\
\text {-hypertrophic cardiomyopathy } \\
\text {-structural congenital heart disease }\end{array}$ & 3 \\
\hline
\end{tabular}

Figure 1 The FLAME score. Risk factors and their weightings comprising the FLAME Score. AF, atrial fibrillation.

\section{Score performance: California}

A total of 882 procedures were examined in California among 619 patients. Baseline characteristics and differences compared with London patients are summarised in table 1. The Californian patients had smaller LA $(p<0.0001)$, better left ventricular function $(p<0.0001)$ and less extreme comorbidity $(\mathrm{p}=0.0001)$, leading to a significantly lower FLAME score $(\mathrm{p}<0.0001)$. They were, however significantly older $(\mathrm{p}=0.001)$, with significantly more hypertension $(\mathrm{p}<0.0001)$ and pulmonary disease $(\mathrm{p}=0.002)$, and had tried more AADs $(\mathrm{p}<0.0001)$. The duration of follow-up was also longer $(p<0.0001)$.

Median duration of follow-up after an initial procedure was 2.1 years (IQR 1.0-4.1) and did not differ by FLAME score $(p=0.696)$. The score predicted the outcome following a patient's initial procedure in Kaplan-Meier analysis $(\mathrm{p}<0.0001)$ (figures 2 and $3 \mathrm{~A})$. Score $0-1$ predicted $62 \%$ success, $2-444 \%$, and $\geq 529 \%$ $\left(\mathrm{P}_{\text {trend }}<0.0001\right)$ (table 3). The c-statistic was $0.643(95 \%$ CI 0.600 to 0.687 , Hosmer-Lemeshow test $=0.922$ ).

The score also predicted the outcome following a patient's final procedure in Kaplan-Meier analysis
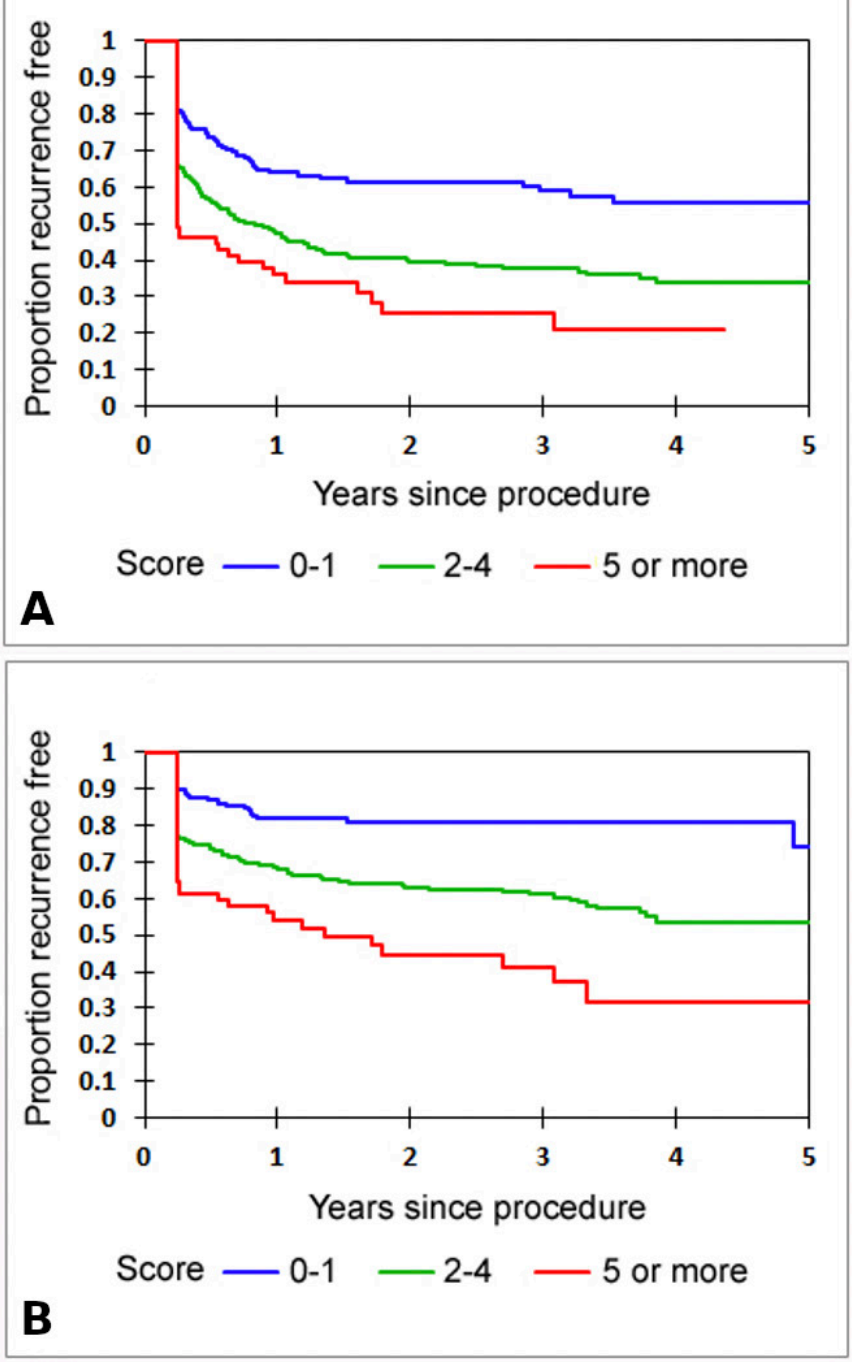

Figure 2 Outcome of ablation in California by FLAME Score group. Kaplan-Meier curves describing freedomf rom recurrence of sustained atrial arrhythmia (by ECG or symptoms) following an initial (A) or final (B) ablation. Curves show FLAME score groups. FLAME, Female, Long-lasting, Atrial diameter, Mitral, Extreme.

$(\mathrm{p}<0.0001)$. Patients underwent mean $1.4 \pm 0.6$ procedures. With increasing score, the number of repeat procedures increased significantly, being performed in $28 \%$ of patients with scores $0-1,40 \%$ with scores $2-4$, and $46 \%$ with scores $\geq 5$ ( $\mathrm{p}=0.001)$ (table 3 ). The median follow-up duration after the final procedure was 1.8 years (IQR 0.8-3.6) and did not differ by FLAME Score $(\mathrm{p}=0.958)$. Score $0-1$ predicted $81 \%$ success, $2 \%-465 \%$, and $\geq 5$ $44 \%$ success $\left(\mathrm{P}_{\text {trend }}<0.0001\right)$ (table 3 , figures 2 and $3 \mathrm{~B}$ ). The c-statistic was 0.690 (95\% CI, 0.645 to 0.734 , HosmerLemeshow test $=0.309$ ).

No individual elements of the score dominated the score's predictive power excessively. The highest c-statistic value for any individual element of the score with respect to outcome following a patient's final procedure was 0.598 (95\% CI 0.550 to 0.646 ) for atrial diameter. 


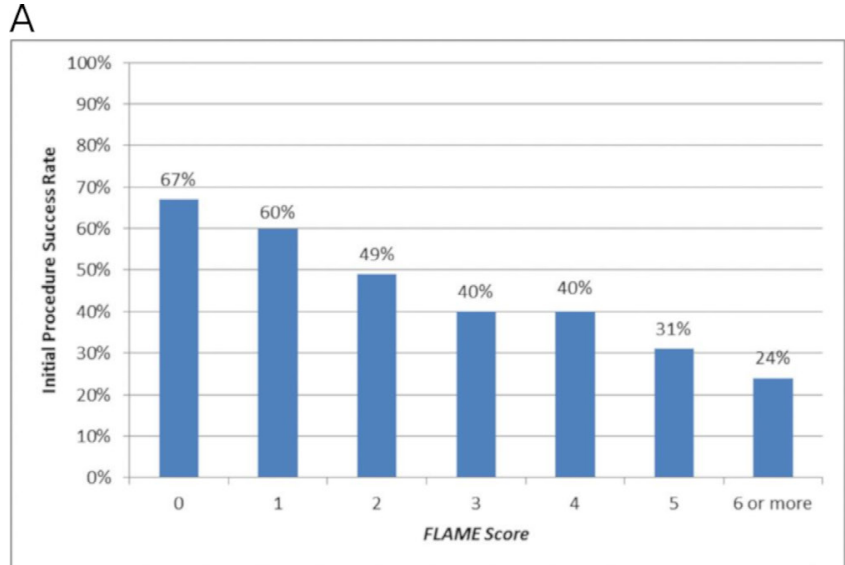

B

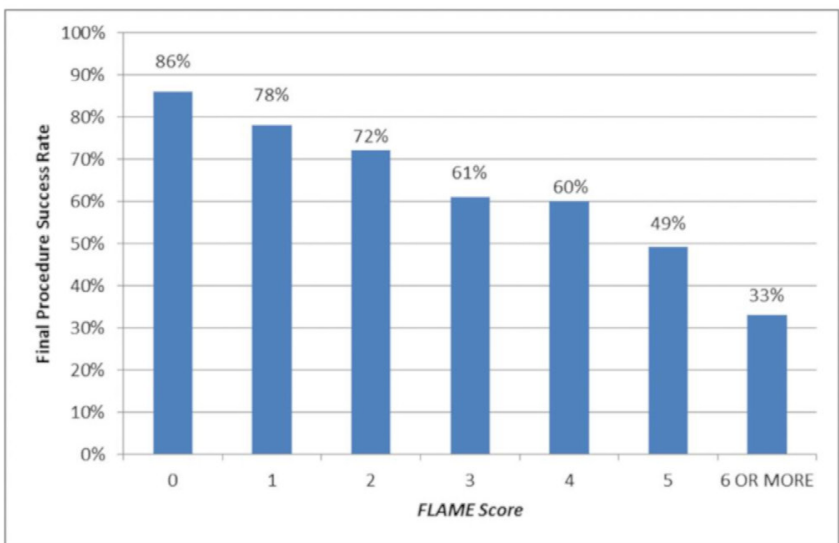

Figure 3 Success rate following the initial $(A)$ and final (B) ablation in California by FLAME score. FLAME, Female, Long-lasting, Atrial diameter, Mitral, Extreme.

\section{DISCUSSION}

The clinically challenging and thereby pertinent cohort of non-PAF patients would benefit from a validated outcome prediction score used before embarking on a journey of ablative therapy. Analysis of IPOs of non-PAF catheter ablations at a London hospital identified independent predictors of outcome from which the easily calculated FLAME score was derived, relevant to the selection of patients for entry into a catheter ablation programme. When validated among patients undergoing non-PAF catheter ablations in California, it effectively stratified the outcomes of both first and multiple procedures. Patients with high scores had reduced success rates following their first procedure, and their final procedure, with fewer maintaining sinus rhythm despite undergoing more repeat procedures than patients with lower scores. Conversely, among patients with a low score $(0-1)$, a success rate of approximately $80 \%$ could be achieved over 5 years of follow-up, and with over $70 \%$ of patients requiring just a single procedure.

The FLAME score is the first cohort-specific (nonPAF) outcome prediction score for patients undergoing radiofrequency ablation. MB-LATER and ALARMEc scores have a singular aim focus on predicting outcomes for repeat ablations, ${ }^{89}$ therefore unable to equip physicians to guide a patient at the beginning of their rhythm management journey, which is crucial. The APPLE and CAAP-AF scores have been developed using both derivation and validation cohorts but are not focused on non-PAF, unlike the FLAME score. ${ }^{10}{ }^{11}$ Furthermore, the APPLE score allocates a point for impaired LV function ( $<50 \%$ ejection fraction), although current evidence recommending ablation as a treatment strategy for improving systolic function. ${ }^{12}$ Despite the proposal of several scores as predictors of AF recurrence following catheter ablation, the FLAME score is unique-the only externally validated score that can predict both initial and multiprocedural success among non-PAF patients.

The variables we found independently associated with the outcome are intuitively understandable and consistent with existing literature. ${ }^{3-6}{ }^{13-19}$ LA diameter is the variable most frequently identified as an independent predictor of non-PAF ablation outcome. ${ }^{35} 6{ }^{13-17}$ Additional predictors that have been identified previously in the multivariable analysis include female sex, ${ }^{3} 4$ 14-16 duration of $\mathrm{AF}^{3}, 46131619$ and valvular disease. ${ }^{5}$ Hypertrophic cardiomyopathy has rarely been examined but was a powerful risk factor for failure when tested. ${ }^{16}$ Structural

Table 3 Success rates and other variables by FLAME score in California

\begin{tabular}{|c|c|c|c|c|c|c|c|c|}
\hline \multirow[b]{2}{*}{$\begin{array}{l}\text { FLAME } \\
\text { score }\end{array}$} & \multirow[b]{2}{*}{$\begin{array}{l}\text { Patientsn } \\
\text { (\%) }\end{array}$} & \multicolumn{3}{|c|}{ Initial procedure } & \multicolumn{4}{|c|}{ Final procedure } \\
\hline & & $\begin{array}{l}\text { Follow-up } \\
\text { months } \\
\text { mean } \pm S D\end{array}$ & $\begin{array}{l}\text { Initial } \\
\text { procedure: } \\
\text { successful }\end{array}$ & $\begin{array}{l}\text { Success } \\
\text { rate }\end{array}$ & $\begin{array}{l}\text { Procedures } \\
\text { per patient } \\
\text { mean } \pm S D\end{array}$ & $\begin{array}{l}\text { Follow-up } \\
\text { months } \\
\text { mean } \pm S D\end{array}$ & $\begin{array}{l}\text { Final } \\
\text { procedure: } \\
\text { successful }\end{array}$ & Success rate \\
\hline 0 & $57(9)$ & $26 \pm 20$ & 38 & $67 \%$ & $1.3 \pm 0.7$ & $24 \pm 19$ & 49 & $86 \%$ \\
\hline 1 & $123(20)$ & $32 \pm 23$ & 74 & $60 \%$ & $1.3 \pm 0.6$ & $28 \pm 20$ & 96 & $78 \%$ \\
\hline 2 & $149(24)$ & $32 \pm 23$ & 73 & $49 \%$ & $1.4 \pm 0.6$ & $28 \pm 20$ & 107 & $72 \%$ \\
\hline 4 & $85(14)$ & $32 \pm 22$ & 34 & $40 \%$ & $1.4 \pm 0.6$ & $26 \pm 20$ & 51 & $60 \%$ \\
\hline 5 & $51(8)$ & $34 \pm 20$ & 16 & $31 \%$ & $1.5 \pm 0.7$ & $28 \pm 18$ & 25 & $49 \%$ \\
\hline 6 or more & $21(3)$ & $32 \pm 19$ & 5 & $24 \%$ & $1.5 \pm 0.5$ & $29 \pm 16$ & 7 & $33 \%$ \\
\hline$P$ value & & 0.696 & & $<0.0001$ & 0.001 & 0.958 & & $<0.0001$ \\
\hline
\end{tabular}

FLAME, Female, Long-lasting, Atrial diameter, Mitral, Extreme. 
congenital heart disease is relevant to few, often younger, patients and has not previously been examined, but seems intuitive, and in our experience, an important risk factor for failure. Our finding that left ventricular dysfunction does not predict ablation failure independently is also consistent with most previous studies. With evidence for improvement in functional status with ablation, ${ }^{20}$ one could argue that for a given FLAME score, ablation is relatively indicated in heart failure patients. In patients with structural congenital heart disease or mitral valve disease, the choices are harder as, while the benefits of sinus rhythm may be greater, the success rate of catheter ablation is lower.

Despite multivariate analysis, important predictive variables may not be identified where data are few or of poor quality, or if the variable is not examined, and the latter situation may lead to alternative confounded variables appearing predictive. Unfortunately, meta-analyses cannot overcome these problems without access to patient-level data. Another critical factor is the inclusion of intraprocedural or postprocedural variables in previous studies, such as AF cycle length, electro-anatomical mapping (ATLAS score), ${ }^{21}$ termination during ablation or early recurrence of AF (MB-LATER). ${ }^{9}$ These may impair the ability to detect important preoperative predictive variables due to confounding, for instance, patients with termination during ablation may also have smaller atria. We, therefore avoided this approach.

With the development of consensus around electrically confirmed pulmonary vein isolation with additional substrate modification as the cornerstone of non-PAF ablation, success rates have plateaued in recent years, ${ }^{7}$ despite ongoing debate around the correct substrate modification techniques to employ. ${ }^{22}$ Preoperative clinical variables, reflecting the severity of the structural and electrophysiological substrate, seem likely to influence success rates irrespective of the exact ablation technique employed, ${ }^{16}$ and our findings confirm this concept.

Our results showed that with FLAME score's 0-4, patients could obtain good long-term results with a mean of $<1.5$ procedures. However, it is important to remember that such a scoring system can only aid in defining one side of a risk-benefit equation, and it does not necessarily follow that high scoring patients should be denied ablation. Weighed against the likelihood of success must be patient' need, which may be particularly pronounced in those who are most highly symptomatic, intolerant of AADs, or haemodynamically compromised. Additionally, the success rates described in this study reflect the 'final procedure' at the time of this study, but not the final clinical outcomes for all patients, many of whom may undergo further procedures in the future. Furthermore, the binary definition of treatment failure used in this analysis may fail to describe the full extent of clinical benefit derived by patients in whom their AF was rendered paroxysmal. However, in the presence of a particularly high FLAME score, the best treatment strategy should be carefully evaluated, and alternative techniques such as surgical or hybrid ablation might be considered.

\section{Limitations}

Several questions cannot be answered within the current study design. An exhaustive list of variables was not examined, such as the history and success of cardioversion procedures, and others may exist which reduce success in some patients. Additionally, although previous studies found LA diameter to perform similarly to LA volume, ${ }^{523}$ and it is more commonly calculated, LA volume may improve prediction at extremes of size. ${ }^{23}$ Like others, ${ }^{5}$ we found that a binary LA diameter less or greater than $50 \mathrm{~mm}$ had predictive power similar to its use as a continuous variable-we chose the latter as, aside from similar statistical power, it seems likely to have a continuous effect. Conversely, duration of non-PAF was tested in a binary manner, in keeping with worldwide definitions and because of the difficulty in determining longer durations accurately; however, we do not know whether it would be more powerful as a continuous variable, nor whether subcategories of persistent AF defined by factors such as a requirement for, or resistance to, electrical cardioversion independently predict outcome. The London population included a minority of patients seen infrequently in other centres, including those with structural congenital heart disease, leading to the unusual finding of the lowest age band having an adverse predictive effect. However, higher age bands had no significant differences in outcome between them, consistent with most other studies, ${ }^{3-6}$ 13-19 $^{13}$ and the score effectively stratified the Californian population where none of the patients had structural congenital heart disease. Intraoperative factors were purposely not tested, which may reduce the specificity of the results, and there was heterogeneity of ablation techniques employed and treatment decisions regarding postoperative AADs; however, our intention was to create a score internationally relevant to current and future practice. Additionally, there was a significant difference in follow-up duration between the populations, although interestingly, the separation of Kaplan-Meier curves observed in the Californian population was almost completed within the duration of the London population follow-up. Finally, in line with international recommendations, while we have used the recurrence of $\geq 30$ s of atrial arrhythmia as our outcome measure, other outcomes such as reduction in the burden of AF or change in the quality of life, could be more clinically meaningful and thus the outcomes described may understate the benefit of this procedure to patients.

\section{CONCLUSION}

The FLAME score, easily calculated from baseline clinical variables, was derived from an analysis of individual procedural outcomes of catheter ablation for persistent $\mathrm{AF}$ in London. It effectively stratified the outcomes of first or multiple catheter ablations for persistent $\mathrm{AF}$ in 
California. Such a score may help to better advise individual patients about the effectiveness of catheter ablation for non-PAF.

Acknowledgements The NIHR Cardiovascular Biomedical Research Unit at the Royal Brompton \& Harefield NHS Foundation Trust, and Imperial College London supported this study.

Contributors JWEJ and RW were responsible for concept and design, data analysis and statistics. JWEJ was responsible for drafting. All authors contributed to the acquisition of data, critical revision of the article and approval of submitted and final versions.

Funding The authors have not declared a specific grant for this research from any funding agency in the public, commercial or not-for-profit sectors.

Competing interests None declared.

Patient consent for publication Not required.

Ethics approval The Institutional Review Board approved the study protocol at both London and California sites.

Provenance and peer review Not commissioned; externally peer reviewed.

Data availability statement Data are available on reasonable request.

Open access This is an open access article distributed in accordance with the Creative Commons Attribution Non Commercial (CC BY-NC 4.0) license, which permits others to distribute, remix, adapt, build upon this work non-commercially, and license their derivative works on different terms, provided the original work is properly cited, appropriate credit is given, any changes made indicated, and the use is non-commercial. See: http://creativecommons.org/licenses/by-nc/4.0/.

ORCID iD

Vennela Boyalla http://orcid.org/0000-0002-0285-171X

\section{REFERENCES}

1 Terasawa T, Balk EM, Chung M, et al. Systematic review: comparative effectiveness of radiofrequency catheter ablation for atrial fibrillation. Ann Intern Med 2009;151:191.

2 Hakalahti A, Biancari F, Nielsen JC, et al. Radiofrequency ablation vs. antiarrhythmic drug therapy as first line treatment of symptomatic atrial fibrillation: systematic review and meta-analysis. Europace 2015;17:370-8.

3 Bhargava M, Di Biase L, Mohanty P, et al. Impact of type of atrial fibrillation and repeat catheter ablation on long-term freedom from atrial fibrillation: results from a multicenter study. Heart Rhythm 2009;6:1403-12.

4 Rostock T, Salukhe TV, Steven D, et al. Long-Term single- and multiple-procedure outcome and predictors of success after catheter ablation for persistent atrial fibrillation. Heart Rhythm 2011;8:1391-7.

5 D'Ascenzo F, Corleto A, Biondi-Zoccai G, et al. Which are the most reliable predictors of recurrence of atrial fibrillation after transcatheter ablation?: a meta-analysis. Int J Cardiol 2013;167:1984-9.
6 Themistoclakis S, Schweikert RA, Saliba WI, et al. Clinical predictors and relationship between early and late atrial tachyarrhythmias after pulmonary vein antrum isolation. Heart Rhythm 2008;5:679-85.

7 Winkle RA, Mead RH, Engel G, et al. Trends in atrial fibrillation ablation: have we maximized the current paradigms? J Interv Card Electrophysiol 2012;34:115-23.

8 Mujović N, Marinković M, Marković N, et al. Prediction of very late arrhythmia recurrence after radiofrequency catheter ablation of atrial fibrillation: the MB-LATER clinical score. Sci Rep 2017;7:40828.

9 Wójcik M, Berkowitsch A, Greiss H, et al. Repeated catheter ablation of atrial fibrillation: how to predict outcome? Circ J 2013;77:2271-9.

10 Kornej J, Hindricks G, Shoemaker MB, et al. The apple score: a novel and simple score for the prediction of rhythm outcomes after catheter ablation of atrial fibrillation. Clin Res Cardiol 2015:104:871-6

11 Winkle RA, Jarman JWE, Mead RH, et al. Predicting atrial fibrillation ablation outcome: the CAAP-AF score. Heart Rhythm 2016;13:2119-25.

12 Turagam MK, Garg J, Whang W, et al. Catheter ablation of atrial fibrillation in patients with heart failure: a meta-analysis of randomized controlled trials. Ann Intern Med 2019;170:41.

13 Nademanee K, Schwab MC, Kosar EM, et al. Clinical outcomes of catheter substrate ablation for high-risk patients with atrial fibrillation. J Am Coll Cardiol 2008;51:843-9.

14 Winkle RA, Mead RH, Engel G, et al. Relation of early termination of persistent atrial fibrillation by cardioversion or drugs to ablation outcomes. Am J Cardiol 2011;108:374-9.

15 Shim J, Joung B, Park JH, et al. Long duration of radiofrequency energy delivery is an independent predictor of clinical recurrence after catheter ablation of atrial fibrillation: over 500 cases experience. Int J Cardiol 2013;167:2667-72.

16 McCready JW, Smedley T, Lambiase PD, et al. Predictors of recurrence following radiofrequency ablation for persistent atrial fibrillation. Europace 2011;13:355-61.

17 Saad EB, d'Avila A, Costa IP, et al. Very Low Risk of Thromboembolic Events in Patients Undergoing Successful Catheter Ablation of Atrial Fibrillation With a CHADS Score $\leq 3$. Circulation 2011;4:615-21.

18 Mohanty S, Mohanty P, Di Biase L, et al. Impact of metabolic syndrome on procedural outcomes in patients with atrial fibrillation undergoing catheter ablation. J Am Coll Cardiol 2012;59:1295-301.

19 Komatsu Y, Uno K, Otomo K, et al. Atrial defibrillation threshold as a novel predictor of clinical outcome of catheter ablation for persistent atrial fibrillation. Europace 2011;13:213-20.

20 Jones DG, Haldar SK, Hussain W, et al. A randomized trial to assess catheter ablation versus rate control in the management of persistent atrial fibrillation in heart failure. J Am Coll Cardiol 2013;61:1894-903.

21 Mesquita J, Ferreira AM, Cavaco D, et al. Development and validation of a risk score for predicting atrial fibrillation recurrence after a first catheter ablation procedure - atlas score. EP Eur 2018;20:f428-35.

22 Verma A, Jiang C-yang, Betts TR, et al. Approaches to catheter ablation for persistent atrial fibrillation. N Engl J Med Overseas Ed 2015;372:1812-22.

23 Parikh SS, Jons C, McNitt S, et al. Predictive capability of left atrial size measured by CT, TEE, and TTE for recurrence of atrial fibrillation following radiofrequency catheter ablation. Pacing Clin Electrophysiol 2010;33:532-40. 